\title{
La gran marcha hacia el Este de las culturas de extremo Occidente y la actualidad de la Ruta de la Seda
}

\author{
The Great March towards the East of the Extreme West \\ and the topicality of the Silk Road
}

\begin{abstract}
Gabriel Terol Rojo $\&$ Manel Ollé Rodríguez
a Universitat de Valencia. gabriel.terol@uv.es

b Universitat Pompeu Fabra. manel.olle@upf.edu

Recibido: 08/04/2018

Resumen: La presente propuesta monográfica para QF 2018 combina la producción literaria comprometida con la ruta comercial histórica por excelencia y la reflexión multidisciplinar en torno a ella misma, en todos los aspectos, $\mathrm{y}$, en ese sentido, escusa un repaso del viaje hacia el Este de las culturales occidentales representadas aquí en el nestorianismo, ese cristianismo primitivo antiguo. Para actualizar la realidad de la Ruta de la Seda se ofrece un repaso de los estímulos más relevantes que en el presente se conglomeran con gran relevancia, necesitados de ordenamiento y planificación sin igual.
\end{abstract}

Palabras clave: Ruta de la Seda; nestorianismo; Oriente y Occidente; literatura de viajes; filosofías comparativas.

\begin{abstract}
The present monographic proposal for QF 2018 combines the committed literary production with the historical commercial route par excellence and the multi-disciplinary reflection around itself, in all aspects and, in that sense, excuse a review of the journey to the East of the Western cultural representations represented here in Nestorianism, that ancient primitive Christianity. To update the reality of the Silk Road offers a review of the most important stimuli that in the present conglomerate with great force, in need of ordering and planning without equal.
\end{abstract}

Keywords: Silk Road; Nestorianism; East and West; travel literature; comparative philosophies. 



\section{Introducción}

Si bien Aristeas de Proconeso, de quien se decía poseedor de la capacidad mágica de abandonar su cuerpo y volver a él a placer, hablaría en el siglo VII a.n.e. de los límites nororientales del mundo conocido en su obra perdida Cantos Arimaspos, no será hasta Herodoto, en su libro IV, cuando las estepas euroasiáticas sean mencionadas documentalmente (Alemany, 2002). Sin embargo, un adecuado tratamiento de la cuestión que ocupa este trabajo sugiere entender que bajo la etiqueta "Ruta de la Seda", relativamente moderna (véanse los dos artículos donde el geógrafo y geólogo alemán la utiliza: Ferdinand von Richthofen, 1876 y 1877), se esconden siglos de comercio e intercambio cultural que toman al cambiante país de China como punto de referencia: inicialmente entre sus vecinos geográficos y poco a poco con el resto del mundo civilizado occidental. Es importante destacar que este recorrido fue ampliándose por intereses comerciales y fue múltiple, es decir, nunca hubo una única "Ruta de la Seda". En raras ocasiones se recorrería en su totalidad y, en este sentido, la conquista romana de Egipto (sobre el 30 a.n.e.) propiciaría el inicio de estas relaciones. Posiblemente, de entre las primeras ocasiones que se encuentran documentadas un recorrido de extremo a extremo de este itinerario fue el protagonizado por la diáspora nestoriana. Su herencia cultural en territorio chino es un hito histórico de interculturalidad singular. Este trabajo repasa, brevemente, su expansión y biografía.

\section{Los imperios occidentales según oriente}

Las profusas investigaciones sobre este circuito económico-comercial con las que se pueden contar en la actualidad y su diversidad de perspectivas propician un análisis abundante en detalles e informaciones (Kuzmina \& Maior, 2008; Pierroti, 2015). En ese sentido, contextualizar la cuestión de la diáspora religiosa occidental hacia oriente suscita un punto de partida interesante en el hecho de salvar la visión occidental (diversos trabajos consolidan esa tradición: Thorley, 1971; Scheidel, 2009; Hansen, 2012, o Jean-Noël, 2015) y ocuparse de la visión de Oriente, representada aquí por la antigua China, de los imperios occidentales de aquella época. De entre ellos, el Imperio bizantino (Fúlǐn, 拂菻) y el Imperio romano (Dàqín, 大秦) son una buena muestra. 
Para ello, el buen trabajo de Hoppál (2011) permite conocer a través de los anales chinos cómo percibían estas sociedades desde oriente y saber cuáles eran sus conocimientos al respecto en relación con su geografía, administración o economía, su comercio y sus expediciones diplomáticas. Resulta muy interesante conocer las similitudes que encontraban y su conclusión general equiparando el nivel cultural de las representantes occidentales con el de la china. En general, desconociendo con exactitud cuál era el idioma que usaban para manejar esa información y considerando que con mucha probabilidad los interlocutores eran comerciantes indios y vietnamitas que en la mayoría de los casos serían informantes de segunda mano, podemos prever que nunca se daría el caso de alguien que viniese directamente desde el lejano occidente y que siendo así, en el caso de comerciantes orientales, muy probablemente fueran incapaces de entender con claridad la sociedad y la administración occidental, romana y bizantina (303). Por tanto, sus descripciones más o menos complejas fueron claramente descriptivas y comparativas. En ese supuesto, la conclusión de reconocer un similar nivel cultural da fe de la admiración que pudieron encontrar en aquellos datos que manejaban. Y aunque estos fueran reducidos posiblemente a provincias orientales del imperio sirvieron para fortalecer una idea general que destaca su carácter utópico y su interés por productos de lujo, así como su capacidad productiva textil. En ese contexto, destaca la inexistencia de referencias sobre religiones o ritos. Ello puede ser entendido como una clara muestra de la escasa capacidad de análisis comparativo y descriptivo de los comerciantes que sirvieron de presuntos informantes, o bien del hecho de que siendo de segunda mano no se percatasen de la posibilidad de unas prácticas religiosas distintas a las suyas. Como fuere, la diáspora religiosa occidental hacia oriente fue, sin duda, un fenómeno novedoso y renovador.

La realidad pasa por reconocer que la zona llamada Eurasia se convertiría en un tapiz cuyo campo quedaría marcado por una enorme complejidad de rutas de ida y vuelta, tanto terrestres como marítimas. Sus viajeros, en la mayoría comerciantes, pero también guerreros, perseguidos, filósofos y misioneros, nutrieron de productos y de costumbres ambos extremos de la ruta constituyéndose, claramente, como mediadores de un comercio global y de una sociedad globalizante. Entre quienes se sirvieron de estas rutas y de estos especializados viajeros destacan los seguidores del cristianismo primitivo al ser proscritos y perder su 
pertenencia a la cristiandad ortodoxa. Un breve repaso del proceso de desarrollo del cristianismo resulta aconsejable.

\section{El cristianismo primitivo: el nestorianismo}

Cuando en el siglo III se convertiría en la organización política más influyente del Imperio romano y un siglo más tarde pasaría a ser la religión principal del Estado, el cristianismo se vio obligado a institucionalizarse y ello se realizó desde una ortodoxia que no dudaría en expulsar la heterodoxia de la diversidad de sus manifestaciones primitivas. De entre ellas, el arrianismo, el monofisismo y el nestorianismo quedarían denigradas. La última de éstas, creada por el patriarca de Constantinopla, el monje Nestorio (Bevan, 2015) defendía una separación total entre los atributos de divinidad y de humanidad de Cristo. Profesaba la necesidad de distinguir la hipóstasis entre Jesús y Cristo, y defendía que la figura de su madre María, al ser responsable sólo de la parte humana de éste, no tenía carácter ni naturaleza divina. Por ello, serían conocidos como "difísitas" en relación a su defensa de "dos naturalezas" en Jesucristo. Obviamente enfrentado con los defensores de la unicidad de Jesucristo, entre ellos el patriarca de Alejandría; el nestorianismo fue condenado, junto al Pelegianismo (doctrina que negaba la existencia del pecado original, atribuyéndola en exclusiva a Adan y, por tanto, liberando a la humanidad de esa carga/pecado de nacimiento), en el concilio de Éfeso del 431, conocido como el III Concilio Ecuménico. La diáspora de seguidores, monjes y sacerdotes del nestorianismo hacia el este resulta un hito en la historia de la ciencia y del pensamiento occidental.

Geográficamente podemos analizar el legado nestoriano por oriente, presumiblemente a través de las activas rutas comerciales, y señalar como primer destino el Imperio sasánida donde empezaron a proliferar iglesias difísitas (Vine, 1937). Numerosos habitantes de la actual Irak abrazaron esta religión, hasta llegar a conformar una dinastía cristiana conocida como "lájmidas o lajmíes" y también "munadhíridas". Es en ese momento, en el siglo VII, cuando empiezan a expandirse hacia el este las primeras misiones nestorianas, hasta alcanzar Asia central, India, China e incluso Mongolia y Rusia, así como Manchuria. Con las invasiones musulmanas y la conquista del imperio persa en el 644, la comunidad cristiana fue relegada a una mínima representación y bajo 
la protección directa del gobernante correspondiente ostentarían cargos de educadores, siendo tratados como "dhimmi". En ellos recayó la responsabilidad de transmitir el conocimiento científico y la filosofía grecorromana (con especial atención a la doctrina aristotélica) y actuar como médicos occidentales. Su responsabilidad en la conversión de textos antiguos griegos traducidos al siríaco para su difusión en el mundo árabe no solo propició el progreso científico musulmán, sino que permitió que fueran divulgados en lengua árabe posteriormente, y de ahí al latín para la Europa occidental, impidiendo, de este modo, su pérdida y desaparición. La tradición y sincretismo de estos nestorianos y de la cultura islámica se extenderán en el tiempo aportando innumerables beneficios culturales y de conocimiento.

En la actualidad estas comunidades, repartidas por todo el mundo, sobreviven en el extenso territorio de Eurasia con diferente fortuna. Con el nombre de "asirios" o "nasranim" (nazarenos) se los puede encontrar perseguidos en Irak, Siria e Irán y dispersos en la India (véase: Gaunt, 2011 y 2012; Donabed, 2015). De estos primeros podemos distinguir los llamados "kaldani" o cristianos caldeos auténticos representantes de las Iglesias orientales que aún utilizan la lengua siríaca como lengua litúrgica (Yacoub, 1995). Recientes investigaciones doctorales sobre esta temática confirman su importancia y actualidad (Mar Aprem, 2000; Bek, 2003 y/o Cho, 2014). Especial mención merece el trabajo recopilatorio de la producción textual de la Iglesia siríaca oriental editada por Dorothea Weltecke (2012). De igual modo, la inestabilidad política reciente de la zona ha generado diversos e interesantes estudios sobre interreligiosidad e identidad religiosa (Seleznev, 2014; Woźniak, 2011 y 2014).

Entre aquellas misiones hacia extremo oriente de los primeros nestorianos destacarían los contactos con los turcos orientales (uigures) y primitivas tribus mongoles. No hay duda de que la evidencia más clara de su estancia e importancia social en la época viene a establecerse en el monumento que se erigió en el siglo VIII (concretamente en el 781), conmemorando su llegada y datando esta en el 635. Este monumento en forma de estela de piedra caliza contiene 1756 caracteres chinos y 70 palabras en siríaco y da fe del reconocimiento por el mismísimo emperador chino Taizong (segundo emperador de la dinastía Tang) de la convivencia del nestorianismo y la sociedad china. Entre el texto puede hallarse una mención a un personaje llamado Alopen, y según la teoría 
del investigador japonés Yoshiro este nombre en chino podría ser una transcripción de Abraham (Yoshiro, 1937); a quien se le reconoce como posiblemente el primer misionero cristiano en llegar a China y que sería merecedor del reconocimiento imperial de "guardián de la gran doctrina". Identificado como un monje siríaco provendría de territorios del imperio sasánida y, a través del circuito comercial de la Ruta de la Seda, llegaría hasta el final de esta en la actual Xi'an (capital de la China de los Tang llamada Chang an). La primera difusión que se realizó de esta estela se encuentra en la obra del siglo XVII China illustrata (Athanasius Kircher, 1667), y aunque inicialmente generó dudas sobre su autenticidad, en la actualidad esta no se encuentra bajo sospecha alguna y se encuentra en el Museo de Berlín. Sin duda, con ella se dinamizó el estudio del nestorianismo en Asia y se personalizará el trabajo olvidado de numerosos misioneros y sacerdotes.

Quizás el más popular de aquellos nestorianos sea el pastor Juan (Preste Juan) y represente una muestra del modo como la Europa medieval recibía las noticias provenientes del lejano oriente. Por un lado, ahondaría en la imagen estereotipada de las excelencias orientales y, por otro, alimentaría empresas utópicas a la par de la búsqueda del Santo Grial o el Arca de la Alianza. Los viajeros medievales tuvieron en la imagen que representaba la sociedad y el reino de esta figura mítica nestoriana un mito similar al del Dorado o la Fuente de la Eterna juventud y ello estimuló muchas expediciones y viajes.

Parece ser que, en el siglo XII, el papa Eugenio III recibiría una carta de un sacerdote cristiano nestoriano. Supuestamente descendiente del rey mago Melchor, en ella se describía un reino abundante en riquezas y en donde, entre sus atributos, destacaba el que ninguno de sus súbditos conociera el hambre. Investigaciones actuales (Baum, 2002 y Paolillo, 2009) aúnan diversos estudios para testificar de qué manera estas noticias sirvieron para promover múltiples expediciones en su búsqueda. De todas ellas, fueron las de los portugueses encabezados por el famoso Enrique el Navegante, auténtico iniciador de la Era de los descubrimientos portugueses, quien en su interés por explorar el continente africano (XIV) y al hilo de la civilización etíope creyeron haber encontrado ese reino. Finalmente, la búsqueda de ese Eden en la Tierra finalizó sin su hallazgo en el siglo XVI. Y los trabajos modernos reflejan los intereses que propiciaron la invención de este personaje y de sus consecuencias (Knefelkamp, 1988). 
Un estudio interesante que puede profundizar en la expansión de la Iglesia nestoriana por territorio chino en aquella época a través de los recursos chinos es la obra del investigador de la Universidad griega de Ioánina Michael Kordosis (Kordosis, 2008). En ella, se sirve de las principales crónicas imperiales y obras de la dinastía Tang y del texto de la estela de Xi'an para analizar la entrada y expansión de este movimiento religioso extranjero en China.

\section{Actualidad de la Ruta de la Seda}

El Mundo actual se encuentra en un cambio sin igual. Las relaciones internacionales van a alterar el orden histórico y, de entre ellas, las que competen a ese binomio estigmatizante de Oriente y Occidente van a transformarse notablemente. Sobre ese escenario y espoleadas por el sistema geoeconómico, la tradicional "Ruta de la Seda" se transforma en una dinamizante excusa para protagonizar y diseñar un escenario de intercambio sin parangón. Por un lado, los planes chinos al respecto conocidos por su acrónimo en inglés OBOR (One Belt, One Road), la "Ruta de la Seda del siglo XXI" tuvo que ser modificado para salvar controversias por BRI (Belt and Road Initiative), en español IFR ("Iniciativa de la Franja y la Ruta"), remarcando las múltiples sensibilidades que existen de trasfondo. La magnitud del proyecto es enorme y el resumen de Dirmoser (2017) es elocuente: compete a 65 países, cuya población general oscila entre los cuatro mil millones, y representa un $35 \%$ del comercio mundial. No tardando en ser considerado como un Plan Marshall contemporáneo. Sin duda, su "gigantismo" alberga su importante trascendencia.

El estatus de potencia global hacia el que China se dirige a gran velocidad propicia convertir este proyecto en una iniciativa de cooperación universalista única, conectando Asia, Europa y África en clave económica, energética, de transporte, comunicación y, sin duda alguna, cultura. Y el papel de España no es menor, ni debería resignarse a serlo fuera. Las oportunidades que suscita, los retos y las recomendaciones centran los más actuales trabajos al respecto (Beneyto \& Fanjul, 2018b). La promoción de una participación activa que considere sus dificultades es una tarea de futuro (2018a) y las oportunidades son ineludibles (Ríos, 2018). 
Heredera del importante interés que la seda despertó comercialmente en Occidente, un hilo que por siglos ha unido a ambos territorios (Niglio, 2012), que aunaría esfuerzos, desarrollo y competitividad comercial por ejemplo entre Italia y España (Navarro, 2016) o, especialmente, comprometería el pasado artesanal de la ciudad de Valencia, la actual IFRI trasciende este producto estrella y dinamiza el fruto de las relaciones comerciales globales en lo que se ha descrito como "la Ruta de la Seda electrónica" (Chander, 2013). Sin duda, de esa primera fase de mistificación, admiración, orientalismo y legendarismo asociada a Oriente, el paso al estudio y comprensión de las culturas lejanas ha desencadenado una global occidentalización y su retorno va a desarrollar un nuevo orden mundial y una nueva hegemonía global. De la seducción por el chinoiserie y/o el japonismo, esa tendencia en los lenguajes ornamentales (Almazán, 2003) propia de tiempos no tan alejados, la IFRI proyecta una relación descolonial entre las culturas del mundo, principalmente las etiquetadas tradicionalmente como orientales y occidentales, que reescribe cualquier pronóstico previsto con anterioridad a este descomunal proyecto. Modernidad/postmodernidad son concebidos desde la reivindicación de una interdisciplinariedad (Mignolo, 2008) tan plural como el comercio que alimenta la IFRI.

\section{Conclusiones}

En resumen, la "Ruta de la Seda", tanto por la riqueza literaria de su recorrido geográfico como por las implicaciones culturales que propició, convierte a este eje en un itinerario de interculturalidad y un auténtico crisol de diferencias.

No exclusiva y restrictivamente de importancia comercial y económica, el valor más relevante de la Ruta de la Seda, tanto religiosa, cultural y socialmente, determina una prolija producción literaria. Su principal característica involucra a una generosa diversidad etnográfica repartida por todo su itinerario que intensifica la mera interconexión de una lejanía, representada por Asia, con una cercanía, representada por el Mediterráneo occidental, y viceversa. Por ello, no podemos obviar que en la biografía de este circuito comercial, la historia, importancia y repercusión contextual de la ciudad de Valencia juegan un papel significativo y, potencialmente, de referencia en trabajos especializados como los que seleccionaremos. 
En definitiva, el monográfico "La Ruta de la Seda y sus literaturas" augura una amplia variedad de perspectivas y se entiende como un lugar de encuentro de reflexiones hermenéuticas, literaturas contrastivas y estudios literarios de notable interés académico.

Por ello, reúne una selección de trabajos comprometidos con estos contenidos que representan las últimas investigaciones, preocupaciones y comparaciones culturales desde una perspectiva literaria. Sus autores son una buena muestra de este estudio y de su compromiso a aportar conocimiento e investigación académica al respecto:

Chiara Olivieri analiza los procesos de asimilación identitaria de los uighures del Xinjiang en el ámbito chino desde la dinastía Qing hasta la formulación de los proyectos de las nuevas rutas de la seda en su artículo "Estepa y rutas de la seda frente al espejo de la Región Autónoma Uigur de Xinjiang. Fronteras fluidas y construcción de narrativas histórico-identitarias".

Teresa Tejeda reflexiona en su artículo "Imágenes de la mujer en Sueño en el Pabellón Rojo. La construcción y la transgresión del género" sobre la imagen de la mujer en la literatura china del siglo XVIII a través del análisis de los personajes femeninos más importantes de la novela china Sueño en el Pabellón Rojo, así como de dos de los protagonistas que cuestionan los límites del estereotipo.

Karolina Zygmunt estudia en su artículo "La Ruta de la Seda: entre el relato medieval, la novela histórica y los textos contemporáneos" la recreación literaria contemporánea del trayecto de la Ruta de la Seda a partir de las obras medievales que se refieren a los viajeros medievales que la recorrieron. Se centra para ello en el estudio de los ecos del relato medieval de la Embajada a Tamorlán como fuente de las novelas y narraciones históricas de Fernando Martínez Laínez, Embajada a Samarcanda, y de Miguel Silvestre, Emoción del nómada.

Min Sun y José María Escribano Angulo estudian en su artículo "La influencia cultural china en la España moderna: encuentros y desencuentros" la influencia de la imagen de China en las letras españolas y las historiografías de los siglos XVI y XVII. Se analizan con mayor detalle las descripciones de China y algunos tópicos literarios vinculados a China recurrentes en algunos de los más destacados autores del siglo de Oro.

Alexandre Bataller Català escribe sobre "La representació de la dona sericicultora en textos literaris valencians de la Renaixença, l'eco 
de Frederic Mistral", y muestra la relevancia del cultivo de la sedería como actividad agrícola e industrial en Valencia con la producción literaria valenciana.

María José López Terrada y Ester Alba Pagán, con "Pintores y ornatos para los Tejidos de seda en la Ilustración y la Academia Valenciana de Bellas Artes", destacan la relevancia de Valencia como centro principal manufacturero español y del papel de la Escuela de Flores, Ornamentos y otros diseños adecuados para Tejidos del siglo XVIII.

Alexandra Magdalena Mironesko y José Ramón Magdalena Nom de Déu, en "China y el Lejano Oriente en el relato de Benjamín de Tudela (siglo XII). Realidades y fantasías", centrándose en la figura emblemática del viajero y escritor medieval español, ahondan en la literatura de viajes para presentar y analizar la diversidad de informaciones de múltiple naturaleza que estos textos ofrecían.

Y David García Ponce estudia, a partir de tres autores componentes de la Edad de Plata de la literatura española: M. ${ }^{a}$ Teresa León, Rafael Alberti y César M. Arconada, su viaje por la China maoísta, mezcla de fascinación y disidencia, en "La imagen de China en la literatura del exilio y la configuración de un paisaje cultural", simbólicamente una muestra del viaje de Occidente a Oriente en el contexto intercultural de la Ruta de la Seda.

En definitiva, una selección de variados trabajos actuales representativos del viaje de ida y vuelta de las culturas, lenguajes, relaciones y sociedades, merced al más importante y actual canal de comunicación de la Humanidad

\section{Bibliografía}

Alemany i Vilamajó, A. 2002. Maes Titianos I la Torre de Pedra (I): una font grega sobre els orígens de la ruta de la seda. Faventia 24(2), 105-120.

Almazán Tomás, D. 2003. La seducción de Oriente: de la Chinoiserie al japonismo. Artigrama 18, 83-106.

Baum, W. 2002. Der Priesterkönig Johannes und die syrische Christenheit. En Tamcke, M. (ed.) Syriaca. Zur Geschichte, Theologie, Liturgie und Gegenwartslage der syrischen Kirchen. 2. Deutsches Syrologen-Symposium (Juli 2000, Wittenberg). Studien zur Orientalischen Kirchengeschichte 17. Münster: LIT, 177-184. 
Bek, F. M. 2003. Die christliche Minderheit in Syrien - Versuch einer Gegendarstellung über bisher verbreitete Ansichten über die christliche Minderheit in Syrien, die es seit der zweiten Hälfte des 19. Jahrhunderts nicht mehr gäbe (Ph.D. dissertation). Rheinischen Friedrich-Wilhelms-Universität zu Bonn.

Beneyto, J. M. \& Fanjul, E. 2018a. La nueva Ruta de la Seda: Recomendaciones para promover la participación española. Madrid: Instituto Universitario de Estudios Euroepeos-CEU Ediciones.

Beneyto, J. M. \& Fanjul, E. (dir.). 2018b. El papel de España en la nueva Ruta de la Seda. Oportunidades, retos, recomendaciones. Cizur Menor: Editorial Aranzadi.

Bevan, G. A. 2015. Nestorius of Constantinople. En Parry, K. (ed) Wiley Blackwell Companion to Patristics. Malden, MA: Wiley-Blackwell, 197-210.

Chander, A. 2013. La ruta de la seda electrónica. Celebrando el futuro del comercio internacional. Nueva Revista 145, 39-50.

Cho, W. 2014. Beyond Tolerance: "The Mongols" Religious Policies in Yuan-dynasty China and Il-khanate Iran, 1200-1368 (Ph.D. dissertation). Yale University, New Haven.

Dirmoser, D. 2017. La Gran Marcha china hacia el oeste. El megaproyecto de la nueva Ruta de la Seda. Nueva Sociedad 270, 27-38.

Donabed, S. G. 2015. Reforging a Forgotten History: Iraq and the Assyrians in the 20th Century. Edinburgh: Edinburgh University Press.

Gaunt, D. 2011. The Ottoman Treatment of the Assyrians. En Suny, R. G.; Göçek, F. M. \& Naimark, N. M. (ed.) A Question of Genocide: Armenians and Turks at the End of the Ottoman Empire. Oxford: Oxford University Press, 244-259.

Hoppál, K. 2011. The Roman Empire According to the Ancient Chinese Sources. Acta Antiqua. Academiae Scientiarum Hungaricae 51, 263-305.

Jean-Noël, R. 2015. De Roma a China por la ruta de la seda en tiempos de la Roma antigua. Barcelona: Stella-Maris.

Kircheri, Athanasii e Soc. 1667. Jesu China monumentis, qua sacris qua profanis, nec non variis Naturae et artis spectaculis, aliarumque rerum memorabilium argumentis illustrata, auspiciis Leopoldi primi, Roman. Imper. Semper augusti Munificentissimi Mecaenatis. Amsterdam: Johannes Jansson van Waesberg.

Knefelkamp, U. 1988. Der priesterkönig Johannes und sein Reich-Legende oder realität? Journal of Medieval History 14(4), 337-355.

Kordosis, M. S. 2008. T'ang China, the Chinese Nestorian Church and "Heretical" Byzantium (A.D. 618-845). Ioannina: Ioannina University Press. 
Kuzmina, E. E. \& Mair, V. H. 2008. The Prehistory of the Silk Road. Penssylvania: University of Penssylvania Press.

Mar Aprem (Mooken). 2000. The History of the Assyrian Church of the East in the Twentieth Century, with Special Reference to the Syriac Literature in Kerala (Ph.D. dissertation). Mahatma Gandhi University, Kottayam.

Mignolo, W. D. La opción desolonial. Revista Letral 1, 3-22.

Niglio, O. 2012. La seda. Un hilo sutil que, por siglos, ha unido a los pueblos de Oriente y de occidente. Apuntes 25(1), 82-89.

Navarro Espinach, G. 2016. La seda en Italia y España (siglos XV-XVI). Arte tecnología y diseño. En Revista diálogos Mediterránicos, 10, 71-91.

Paolillo, M. 2009. In Search of King George. En Winkler, D. W. \& Tang, L. (ed.) Hidden Treasures and Intercultural Encounters: Studies on East Syriac Christianity in China and Central Asia. Orientalia - Patristica Oecumenica 1. Berlin: LIT, 241-255.

Pierroti, N. 2015. Grandes viajes en la Antigüedad: La expansión del cristianismo primitivo por la Ruta de la Seda. Clio. Revista de Historia 168, $30-41$.

Richthofen, F. von. 1876. Über den Seeverkehr nach und von 8 China im Altertum und Mittelalter. Verhandlungen der Gesellschaft für Erdkunde zu Berlin, 86-97.

Richthofen, F. von. 1877. Über die zentralasiatischen Seidenstrassen bis zum 2. Jh. n. Chr. Verhandlungen der Gesellschaft für Erdkunde zu Berlin, 96-122.

Ríos, X. 2018. The Belt and Road Initiative: An Opportunity for Spain. Sinología hispánica. China Studies Review 6(1), 157-176.

Scheidel, W. (2009). Rome and China: Comparative Perspectives on Ancient World Empires. Oxford University Press.

Селезнёв, Николай Николаевич. [Seleznev, N. N.] (2014). Pax Christiana et Pax Islamica: Из истории межконфессиональных связей на средневековом Ближнем Востоке [Pax Christiana et Pax Islamica: A partir de la historia de las relaciones interreligiosas en el Oriente Medio medieval]. Orientalia et Classica 45. Москва: Российский Государственный Гуманитарный Университет, Институт восточных культур и античности, [Moscú: Universidad Estatal rusa de Humanidades, Instituto de Oriental y Clásica].

Thorley, J. 1971. The Silk Trade between China and the Roman Empire at its Height, Circa a.d. 90-30. Greece and Rome 18(1), 71-80.

Vine, A. R. 1937. The Nestorian Churches: A Concise History of Nestorian Christianity in Asia from the Persian Schism to the Modern Assyrians. London: Independent Press. 
Weltecke, D. (ed.). 2012. Geschichte, Theologie, Liturgie und Gegenwartslage der syrischen Kirchen. Syriaca 40. Wiesbaden: Harrassowitz Verlag.

Woźniak, M. 2011. National and Social Identity Construction among the Modern Assyrians/Syrians. Parole de l'Orient, 36, pp. 569-583.

Woźniak, M. 2014. Współcześni Asyryjczycy i Aramejczycy. Bliskowschodni chrześcijanie w poszukiwaniu tożsamości narodowej [Asirios y sirios modernos. Los cristianos de Oriente Medio en la búsqueda de una identidad nacional]. Łódź: Wydawnictwo Uniwersytetu Łódzkiego. [Editorial de la Universidad de Lodz (Polonia)]

Yacoub, J. 1995. La diaspora assyro-chaldéenne. Istina 40(2), 191-204.

Yoshiro, P. 1937. Nestorian Documents and Relics in China. Tokyo: Toho bunkwa gakuin, 2. (Reed: The Nestorian Monument in China. USA: Forgotten Books, 2015). 